\title{
RIQUEZA PERSONAL Y RUBROS DE INVERSIÓN. TUCUMÁN, ARGENTINA, 1860-1870*
}

\section{PERSONAL WEALTH AND INVESTMENT ACCOUNTS. TUCUMAN, ARGENTINA, 1860-1870}

\author{
Cecilia Alejandra Fandos
}

Universidad Naciona1 de Jujuy, Jujuy, Argentina, <cecifandos@yahoo.com>

\section{María Paula Parolo}

Universidad Nacional de Tucumán, Tucumán, Argentina, <paula_parolo@hotmail.com>

\begin{abstract}
Resumen. Este trabajo se enmarca en un proyecto mayor que estudia la distribución y composición de la riqueza en la provincia de Tucumán durante el siglo XIX. El recorte cronológico corresponde a un punto de inflexión en tanto que la década de 1860 es representativa de los tramos finales de un proceso de transición en la economía y sociedad provincial que desembocó, al promediar el decenio de 1870, en un nuevo modelo productivo impuesto por la agroindustria azucarera. En esta ocasión nos proponemos profundizar el análisis de la composición del capital por rubro de inversión (tierra, ganado, comercio y manufactura) y por segmentos de riqueza (los más ricos, medianamente ricos, menos ricos) en el departamento Capital, donde se concentraban tanto las actividades comerciales como un importante desarrollo agrícola y manufacturero.
\end{abstract}

Palabras clave: distribución de la riqueza; riqueza personal.

Abstract. This work is part of a larger project which studies the distribution and composition of wealth in the state of Tucuman during the nineteenth century. The chronological cut corresponds to a turning point because the ' 60 s are representative of the final stages of a transition process in the economy and provincial society, process that led, in the ' $70 \mathrm{~s}$, in a new production model imposed by the sugar industry. This time we intend to deepen the analysis of the composition of capital by investment categories (land, livestock, trade, manufacture) and wealth segments (the richest, moderately rich, and less wealthy) in the Capital department which focused on both the commercial activities such as a significant manufacturing and agricultural development.

Key words: wealth distribution; personal wealth.

Fecha de recepción: mayo de 2013. Fecha de aceptación: agosto de 2013.

\footnotetext{
* Este trabajo fue realizado en el marco de los proyectos de investigación El Mapa de la Desigualdad en la Argentina del Siglo XIX (PICT 2006-00243), y Estado, Impuestos y Contribuyentes. La Construcción del Sistema Fiscal en Tucumán en el Siglo XIX (PICT-2011-2167), financiados por la Agencia Nacional de Promoción Científica y Tecnológica, Argentina.
} 


\section{INTRODUCCIÓN}

$\mathrm{E}$ ste trabajo se enmarca en un estudio de más largo plazo que procura proyectar el desarrollo de capitalismo en términos de dinámicas, composición y distribución de la riqueza durante el siglo XIX, en una área mediterránea de Argentina -la provincia de Tucumán- que tuvo su pauta de crecimiento económico a partir de la especialización de la industria azucarera para el mercado interno. La mirada se dirige principalmente a dilucidar las formas de generación, reproducción, reparto, acumulación y circulación de la riqueza para evaluar la cuestión en términos de desarrollo social. Esta indagación general -que se conjuga a su vez en un esfuerzo colectivo de varios investigadores-atraviesa la problemática de las relaciones de concurrencia o divergencia entre el crecimiento y la desigualdad. ${ }^{1}$ La investigación, en su especulación teórica, se sostiene, entonces, de este primario y central debate procedente de la economía, sobre el cual actualmente obra como consenso científico la idea de que resulta inverosímil la existencia de leyes generales que rijan los canales de influencia recíproca entre el crecimiento y la distribución, ponderándose la particularidad de cada región y la diversidad de variables explicativas a considerar como la calidad institucional, la dotación de factores, etc. ${ }^{2}$ La historia económica, en la medida que sortea la carencia de datos imprescindibles para efectuar estos estudios, principalmente en etapas preestadísticas, suma sus contribuciones basadas en un fuerte empirismo, la casuística y la reconstrucción de contextos históricos específicos.

En este sentido, la particularidad de la economía tucumana en la década de 1860 residía en el tránsito hacia un formato de capitalismo moldeado por la expansión de la agroindustria, valorado historiográficamente como más equitativo en términos relativos a otros complejos azucareros latinoamericanos. ${ }^{3}$ Efectivamente, la serie de transformaciones que inyectó la actividad azucarera desde mediados del siglo XIX fue crucial al redefinir las relaciones económicas, espaciales, sociales y políticas de un amplio recorte de la geografía nacional. ${ }^{4}$ Siendo desde entonces el eje de la vida económica y política provincial, dicha actividad perfiló un modelo concentrado en su fase industrial en los grandes azucareros, que a la vez in-

\footnotetext{
${ }^{1}$ Este grupo, nucleados por Jorge Gelman, se encuentra abocado a desentrañar desde estas perspectivas los procesos socioeconómicos suscitados en distintas regiones de la actual Argentina tras el quiebre del orden colonial y durante el siglo XIX. Véase Gelman y Santilli, Mapa, 2011.

2 Gallo, "Crecimiento", 2003.

${ }^{3}$ Sobre las variaciones de los complejos azucareros de América Latina, véase Crespo, $A z u ́$ car, 2006. Sobre aspectos más específicos de la cuestión, véase Bolsi y D’Arterio, "Agroindustria", 2005.

${ }^{4}$ Campi, "Notas", 1999.
} 
corporó a un profuso grupo de agricultores independientes, responsables de provisión de la materia prima. Este último grupo llegó a disputar "con las elites el control del agua, el suelo y los beneficios de la explotación del azúcar", logrando que fuera más equitativa la distribución de la riqueza".

Sin embargo, en un primer examen del caso tucumano advertimos que, bajo condiciones específicas signadas por el incremento demográfico, el crecimiento de la producción y la ausencia de fronteras abiertas y de tierras públicas, pasado el medio siglo XIX esta provincia tocaba los techos de la desigualdad social, con Ginis superiores a 0.7 puntos. También revelamos la fuerte concentración de la riqueza inmobiliaria, ganadera y comercial en el área circundante a la zona capitalina de San Miguel Tucumán, que constituía el principal epicentro del crecimiento económico de la época y disparaba en una mayor inequidad relativa a otras regiones de la provincia. ${ }^{6}$

Lógicamente, nuestro centro de interés es muy amplio, apunta a una problemática compleja y laboriosa que requiere de la comparación diacrónica y espacial. En este sentido, podemos sólo ir despuntando el análisis paso a paso. En esta ocasión, hacemos un recorte de la realidad del gran proceso hacia la década de 1860 y del área capitalina de la provincia de Tucumán, que por acotados no merman su significación. En primer lugar, el recorte cronológico corresponde a un punto de inflexión muy referido historiográficamente, en tanto que para un conjunto de autores esa década es representativa de los tramos finales de un proceso de transición en la economía y sociedad provincial que desembocará, al promediar el decenio siguiente, en un nuevo modelo productivo impuesto por la agroindustria azucarera. En segundo lugar, la particularidad del departamento Capital como área que lideraba las transformaciones resulta incuestionable.

En este marco temporal y espacial nos proponemos, entonces, profundizar el análisis de la composición de la riqueza existente por rubro de inversión (tierra, ganado, comercio, manufactura) y por segmentos sociales de riqueza (muy ricos, medianamente ricos y menos ricos). Para ello recurrimos a fuentes fiscales: los padrones de contribución directa inmobiliaria (impuesto sobre propiedad territorial), mobiliaria (ganado y cereales), y los registros de patentes (impuestos sobre negocios de comercio y establecimientos de manufacturas). Estas cargas tributarias se calculaban sobre el capital "en giro" o invertido en cada una de las actividades gravadas.

Entendemos que preguntarnos por la distribución de la riqueza personal entre los diferentes rubros de actividad supone explorar la estructura económica y productiva de la provincia -especialmente del departamento

\footnotetext{
${ }^{5}$ Hora, Historia, 2010.

${ }^{6}$ Parolo y Fandos, “Tierra”, 2011.
} 
Rectoral o Capital- durante un periodo que la historiografía tucumana coincidió en tildar de "transición". Asimismo, la inquietud por develar en qué invertían sus capitales los contribuyentes tucumanos según su capacidad de acumulación, requiere de un reconocimiento previo de la composición de la sociedad de la que los tributantes formaban parte, así como de la ubicación de cada uno de ellos en los diferentes estratos o niveles de riqueza. Finalmente, en el marco de la estructura económica y social del momento, analizamos la distribución de los capitales acumulados en cada uno de los segmentos de contribuyentes, entre los diferentes rubros de actividad predominantes en el espacio examinado.

\section{LA ECONOMÍA TUCUMANA EN LA DÉCADA DE 1860}

Hacia mediados del siglo XIX, la economía provincial se había consolidado sobre la base de una dinámica actividad mercantil sustentada en un flujo comercial orientado a varios mercados de exportación e importación: el Litoral argentino, el mercado regional de las provincias vecinas y el comercio con Chile y Bolivia. En esta triple articulación mercantil, Tucumán pudo colocar no sólo los excedentes de sus producciones primarias, sino también artículos manufacturados con un importante valor agregado. Efectivamente, sobre la base de una diversificada producción agropecuaria y del predominio de pequeñas unidades de producción, también registró un importante desarrollo artesanal y manufacturero, producto del procesamiento de materias primas, algunas de las cuales marcaron ese rumbo exportador de la economía provincial (suelas, artesanías de cuero, cigarros, quesos, azúcar y aguardiente). ${ }^{7}$

Del control de ese comercio y de la inversión directa en la producción de manufacturas había surgido un sector social que, entre 1840 y 1870, acumuló capitales que comenzaron a reorientarse paulatinamente hacia la creciente y cada vez más rentable actividad azucarera. En la década de 1860 se fueron perfeccionando los métodos de producción e importando alambiques, fondos y trapiches, con lo cual se inició el equipamiento de los ingenios con maquinaria de avanzada, de origen europeo. Según las fuentes impositivas, este perfil manufacturero y artesanal fue afirmándose a lo largo de la década -según lo demuestra la participación relativa de estas actividades en la recaudación de impuestos- en desmedro de las actividades comerciales. ${ }^{8}$

${ }^{7}$ Sobre la economía tucumana durante el siglo XIX véanse Giménez, "Interior”, 1975; López, Dueños, 2003; Campi, "Economía”, 2000, e "Ingenios", 1999.

${ }^{8}$ Campi, "Economía”, 2000, p. 15, y Parolo, "Presión”, 2011. 
De manera simultánea a este auge del azúcar, la tradicional actividad ganadera y, en parte, las actividades comerciales fueron perdiendo el peso relativo que tenían anteriormente en la economía de la provincia. Promediando la década de 1850 el sector azucarero era el de mayor dinamismo y el que atraía crecientemente los recursos excedentes de los demás. En esos años, La Nueva Revista de Buenos Aires publicó un par de artículos sobre Tucumán en los que quedaron claramente descritas las transformaciones económicas a las que hicimos referencia. Uno de ellos afirmaba: "Aquí han desaparecido el aspecto de los establecimientos de ganadería para dar lugar a los industriales que van extendiéndose desde la ciudad en todas las direcciones, y el viajero se introduce en un sinnúmero de calles de 'Nápoles' que sirven de cerco a las labranzas de caña de azúcar y a las curtidurías, principales industrias del país". ${ }^{9}$

El escenario de esa transformación fue principalmente la capital provinciana. Para entonces en Tucumán todavía predominaba la población rural (53.5\%), pero San Miguel ya significaba un importante conglomerado urbano, donde se concentraba el grueso de los establecimientos comerciales (tiendas, pulperías y boliches). La zona rural del departamento Capital ofrecía un importante desarrollo agrícola, con cultivos de maíz, trigo, arroz, tabaco, frutales y caña de azúcar, a la vez de ser la principal sede de establecimientos manufactureros tales como ingenios azucareros, destilerías de aguardientes, molinos harineros y curtiembres.

En efecto, la ciudad presentaba la radicación más valiosa de los bienes económicos de toda la provincia, tanto en la propiedad inmueble $(76 \%$ de los capitales respectivos) como mueble (61.5\% de los mismos), esta última principalmente por el gran protagonismo del comercio y la industria. Luego, su estructura social era más inequitativa y más concentrada: $10 \%$ de la población más rica disponía casi de $60 \%$ de los capitales contabilizados; mientras que en la campaña $10 \%$ de este tipo de población concentraba $53.6 \%$. La brecha entre los más ricos y los más pobres era mayor pues el contribuyente con más capital tenía 355 veces más que el de menor capital, y en el área rural la proporción se reducía a $62 .^{10}$

De modo que la expansión económica plasmada en la mayor riqueza general del departamento Capital (área por excelencia de eclosión de la actividad azucarera en las décadas de 1850 y 1860) aconteció con patrones de mayor desigualdad social que en el resto de la provincia. Como posibles lógicas explicativas de esta tendencia, en el área capitalina debe contemplarse que el acceso a los bienes económicos iba cercenándose, pues

${ }^{9}$ La Nueva Revista de Buenos Aires publicada bajo la dirección de Miguel Navarro Viola y Vicente Quesada, Buenos Aires, 1863, t. II, pp. 296-307, en Lizondo, Tucumán, 1916, p. 274.

${ }^{10}$ Parolo y Fandos, “Tierra”, 2011, pp. 278-283. 
su crecimiento económico y especialización azucarera se combinaban con una mayor presión demográfica, producto principalmente de las migraciones regionales estacionales, de la creciente valorización de la propiedad (obligando a un uso más intensivo) y de los procesos de proletarización. ${ }^{11}$

\section{LA ESTRUCTURA SOCIOOCUPACIONAL EN EL DEPARTAMENTO CAPITAL EN 1869}

Según los datos del censo nacional de $1869^{12}$ el departamento Capital se dividía en tres secciones: el área central de la ciudad de Tucumán; los suburbios y su campaña. Las dos primeras, consideradas urbanas, albergaban a 17438 individuos (46.5\%) de los 37539 que residían en el departamento. La pirámide por sexo y edad resultante de las cifras del recuento total de habitantes de estas secciones permite observar que se trataba de una población joven, con predominio de mujeres en todas las cohortes de edades, las que llegaban a duplicar la población masculina a partir del segmento correspondiente a los 41-50 años. Por otra parte, el resumen general de datos del censo de 1869 arroja un perfil ocupacional en el que prevalecían las ocupaciones femeninas ligadas a la manufactura textil (bordadoras, tejedoras, hiladoras, torcedoras) y a los oficios artesanales (carpintero, herrero, sastre, zapatero) entre la población masculina. Los sirvientes, de ambos sexos, representaban alrededor de 14\% de los censados con ocupación declarada, mientras que las tareas domésticas (planchadoras, lavanderas, cocineras), las ocupaciones rurales (criador, labrador, capataz) y los peones representaban cada uno 10\% del universo laboral. El comercio, en cambio, parecía reservarse a una minoría ya que no superaba el 5\% de los individuos con ocupación declarada (véase cuadro 1).

En consecuencia, el perfil ocupacional que arrojan los datos del recuento general del censo permite reconocer un importante porcentaje de individuos $(60 \%)$ en relación de dependencia (peones, sirvientes, empleadas domésticas, manufactura textil), seguidos por $27 \%$ de trabajadores con cierta independencia (artesanos, criadores, labradores) y una minoría de individuos ligados a actividades mercantiles y de transporte.

Pero estas cifras poco nos dicen sobre la posición social de quienes desempeñaban estas ocupaciones. Para develar la estructura socioocupacional del departamento Capital, resulta necesario recurrir a algunas precisiones respecto de estas categorías. De la exploración de las cédulas censales de 1869 (planillas en las que se volcaron los registros de cada

${ }^{11}$ Campi, “Notas”, 1999, y “Azúcar”, 2002.

${ }^{12}$ Primer, 1872. 


\section{CUADRO 1. PROFESIONES EN TUCUMÁN CAPITAL SEGÚN EL CENSO DE 1869}

\begin{tabular}{lrc}
\hline Ocupaciones & Cantidad & Porcentaje \\
& & \\
Sirvientes(as) & 2517 & 13.9 \\
Peón/jornalero $^{\text {Artesanos/oficios }}$ & 1812 & 10.0 \\
Empleadas domésticas $^{\mathrm{a}}$ & 3040 & 16.8 \\
Ocupaciones rurales $^{\mathrm{b}}$ & 1925 & 10.6 \\
Manufactura textil $^{\mathrm{a}}$ & 1855 & 10.2 \\
Comercio $^{\mathrm{c}}$ & 4484 & 24.7 \\
Otras $^{\mathrm{d}}$ & 842 & 4.6 \\
Total & 1663 & 9.2 \\
\hline
\end{tabular}

${ }^{a}$ Exclusivamente femeninas.

${ }^{\mathrm{b}}$ Agricultor, cañero, labrador, hacendado, estanciero, capataz.

${ }^{\mathrm{c}}$ Comerciante, pulpero, abastecedor, tropero, fletero.

${ }^{\mathrm{d}}$ Barbero, barraquero, blanqueador, mendigo, tonelero, posero, retratista, preceptor, escribano, sereno, sacerdote, boticario, amasadora, tamalera, verdulera, prostituta, pastelera, velera, etcétera.

Fuente: elaboración propia de acuerdo con Primer, 1872, pp. 506-512.

uno de los individuos censados) y del cruce con otras fuentes que reflejan algunos rasgos de la sociedad tucumana decimonónica (diarios de viajeros, memorias descriptivas, testamentarias, nóminas de contribuyentes, etc.), obtuvimos un perfil socioprofesional más definido.

Los datos obtenidos muestran una población en la que prevalecían las actividades artesanales, manufactureras, entre los hombres, y el servicio doméstico, entre las mujeres. Con un bajo porcentaje (respecto a los departamentos de campaña) de peones y jornaleros de ambos sexos; un importante sector de comerciantes, de costureras y trabajadoras textiles. Esta sociedad en la que 50 años antes predominaba por amplio margen la servidumbre, se ha transformado -al menos para la población masculinaen una sociedad con mayor complejidad y división del trabajo. Casi 70\% de los hombres con ocupación fueron definidos como artesanos, como comerciantes o dentro de actividades u ocupaciones que les permitían subsistir con relativa independencia. Para las mujeres, sin embargo, seguía siendo el trabajo doméstico el que absorbía la mayor cantidad de mano de obra, aunque las actividades textiles y de confección, así como la elaboración de productos caseros por cuenta propia (empanaderas, tamaleras) se presentaban como alternativas para el servicio doméstico. 
Asimismo, si exploramos la composición interna de cada una de estas categorías ocupacionales, es decir, los atributos comunes que los actores sociales compartían para ser incluidos en una u otra e indagamos en las connotaciones sociales contenidas en cada una de ellas, emana una primera imagen de diversidad y heterogeneidad. En efecto, en el mundo urbano tucumano coexistieron comerciantes, mercaderes, pulperos, troperos, artesanos y un amplio sector de la sociedad ocupado bajo formas de trabajo en relación de dependencia (sirvientes, jornaleros, artesanospeones, criados, conchabados, agregados); todos ellos distribuidos en una pirámide socioocupacional en la que se distinguían diferentes niveles de prestigio, poder y patrimonio. En la cúspide una elite claramente definida, constituida tanto por hacendados, agricultores y terratenientes, como por comerciantes mayoristas, pulperos y troperos, en su mayoría propietarios de inmuebles, algunos de los cuales reorientaron sus inversiones hacia la agroindustria del azúcar en el último tercio del siglo XIX. En la base de la pirámide también se definían claramente aquellos sectores que compartían la característica de estar ajenos al mundo del prestigio y el poder, que trabajaban en relación de dependencia, y sobre quienes recaían las normativas de disciplinamiento social, moral y laboral. El centro de la pirámide se caracterizaba -a diferencia de la cúspide y la base- por una gran pluralidad. Pequeños y medianos criadores y labradores, capataces con tareas de mando sobre las peonadas y algunos maestros artesanos de la ciudad presentaban dentro de su heterogeneidad de caracteres y formas de subsistencia un elemento en común: contaban con medios (una parcela de tierra, un taller, un pequeño peculio) que les permitía sustentarse sin caer en la dependencia del trabajo asalariado, aunque del mismo modo que el universo de "dependientes", estos sectores "medios" de la pirámide social compartían las dificultades económicas y el escaso prestigio social. ${ }^{13}$

\section{CAPACIDAD DE ACUMULACIÓN Y NIVELES DE RIQUEZA}

Una vez reconstruido el contexto económico y el universo social nos preguntamos: ¿cómo determinar los niveles de riqueza en esta estructura social?, ¿ cómo advertir la polaridad entre la riqueza y la pobreza? Sin duda, una tarea mayor que instala grandes disyuntivas si optamos por las herramientas conceptuales que nos brindan las ciencias sociales y, por ello, preferimos apuntalarnos en las propias nociones de riqueza y pobreza de la época. Tomamos indicativos surgidos de fuentes fiscales que nos permi-

\footnotetext{
${ }^{13}$ Sobre la estructura socioocupacional de Tucumán en el siglo XIX, véanse Parolo, "Estructura", 2003; "Actores", 2005, y Ni, 2008.
} 
ten una valoración cuantitativa y cualitativa. Ellos son los montos patrimoniales que marcaban cortes entre los niveles de riqueza y las categorías ocupacionales asociadas o predominantes en cada uno de esos segmentos.

En primer lugar, el mínimo imponible que adoptó la regulación impositiva es donde encontramos los primeros indicios de clasificación o "deslinde" entre niveles de riqueza. La ley de contribución directa sancionada en 1855 estableció para la territorial un gravamen de cuatro pesos por cada 1000 pesos $^{14}$ de capital exceptuando aquellas propiedades cuyo valor fuera menor de ese monto. Los bienes mobiliarios, en cambio, fueron gravados con cinco pesos por cada 1000 , exceptuándose los montos inferiores a 500 pesos para los contribuyentes casados, y a 250 pesos para los solteros. Asimismo, la Ley de Patentes de 1855 dividía a los productores y a los comerciantes en varias categorías según su capacidad productiva o su capital en giro. En esa oportunidad se exceptuó del pago a las pulperías o almacenes cuyo capital fuera inferior a 100 pesos, mientras que al resto se les dividió en tres segmentos: entre 100 y 500 pesos; entre más de 500 y 1000 pesos, y más de 1000 pesos. En el caso de las tiendas no se contemplaba la posibilidad de excepción y se las clasificó en tres categorías: menos de 6000 pesos; entre 6000 y 12000 pesos, y más de 12000 pesos. En 1860 se introdujeron modificaciones en el mínimo imponible, estableciéndose que todos los capitales mobiliarios que alcanzaran los 125 pesos y los territoriales, los 250 pesos, serían comprendidos en el pago de la contribución directa. En 1870, además de incrementarse la alícuota de la territorial a seis pesos por cada 1000 pesos y la mobiliaria a siete pesos por cada 1000 , se bajó el mínimo imponible a 200 pesos para las primeras y 100 pesos para las últimas. ${ }^{15}$

Por otra parte, indagando en las voces de los actores y sus percepciones sobre la riqueza, ${ }^{16}$ encontramos algunas señales sobre los patrimonios y su correlación con la posición de riqueza que de ellos se podía inferir. La mayoría de estas conjeturas se encuentran en los pedidos o reclamos de los mismos contribuyentes ante la Hacienda provincial. Aquellos actores que solicitaron exoneración del pago de impuestos y que se autodefinieron como pobres, muy pobres, o por su notoria pobreza o condenados a vivir de la caridad, refieren poseer bienes inmobiliarios (casita, rancho, cuarto, casa esquina) que variaban entre los 200 y los 1600 pesos. La concesión del pedido por parte del gobierno -además de los estipulados en las leyes de contribución que mencionamos anteriormente- permite inferir que

\footnotetext{
${ }^{14}$ Pesos bolivianos.

${ }^{15}$ Bousquet, Estudio, 1971.

${ }^{16}$ Véanse Solicitudes y reclamos al gobierno, en Archivo Histórico de Tucumán (en adelante AHT), Administrativa y Comprobantes de Contaduría, 1840-1870.
} 
entre esos valores rondaba el primer segmento de los que poseían "algo" aunque su calidad de contribuyente fuera puesta en duda por los mismos actores. Respecto del capital invertido en el comercio, se repiten los pedidos de exoneración por boliches y por pequeños almacenes o pequeñas pulperías que no alcanzaban -según criterio de los solicitantes- los 200 pesos. En sentido inverso, en las presentaciones al gobernador solicitando ayudas económicas para "poner un negocito que permita la subsistencia" se apelaba con frecuencia a montos que iban entre los 200 y 400 pesos, rango de capital mínimo con el que, al parecer, podía abrirse un boliche o pulpería para mantener una familia. Cotejando este dato con los resultados del análisis cuantitativo de los capitales de los contribuyentes por contribución directa en la capital de la provincia en $1869,{ }^{17}$ advertimos que la moda resultante (es decir, el valor que más se repite) es 500 pesos, monto que podría estar indicando la frontera entre los sectores más bajos de riqueza y aquellos desposeídos o pobres, es decir, sin un mínimo de bienes que le permitan sustentarse y mucho menos acumular algún excedente. ${ }^{18}$

Las declaratorias de pobreza arrojaron también algunas pautas para la delimitación de los segmentos de riqueza. En una de ellas, mientras uno de los vecinos que debía testificar sobre la condición de pobre de una mujer viuda afirmó que "aunque tiene una esclava y una casita es pobre, porque tiene una gran deuda"; sin embargo, el juez de primera instancia desestimó el pedido ya que no podía reportarse por pobre si "al momento del matrimonio su marido le hizo una donación de (\$b) 2000 y una esclava de (\$b) 250”. Este valor cobra otro significado si observamos una vez más los resultados del análisis estadístico de los capitales de los contribuyentes que arrojó una mediana (es decir, el valor que se encuentra en el centro de la muestra) justamente de 2000 pesos. Podría inferirse, entonces, que la posesión de ese monto de capital colocaba a un individuo entre los sectores medios de riqueza. Tanto la mediana, 2000 pesos, como el promedio obtenido, 5960 pesos, podrían tomarse, entonces, como indicadores del rango de capitales que habrían acumulado los sectores medianamente ricos.

Encontrar los indicios para determinar el corte entre los sectores medios y los altos o más ricos resulta un poco más complejo. Por un lado, podemos tomar como parámetro la clasificación de patentes por tiendas (negocio que implicaba un capital en giro notoriamente superior al de las pulperías o almacenes ya que se dedicaban al comercio al por mayor y a larga distancia) cuya categoría más alta se estableció a partir de 12000 pesos de capital en giro. A una cifra aproximada hizo alusión Cayetano Rodríguez, importante comerciante tucumano obligado a aportar dinero en

${ }^{17}$ Parolo y Fandos, "Tierra”, 2011.

${ }^{18}$ Sobre las nociones de pobreza en el siglo XIX, véase Parolo, "Nociones", 2005-2006. 
todos empréstitos exigidos durante la primera mitad del siglo XIX, quien en su presentación discriminó los niveles de riqueza dentro del sector más encumbrado:

Bien notorios son los fondos qe. poseen y manejan los Sres. D. José Pose, D. José Mur, D. Pedro Velarde y D. Pedro Garmendia; y yo creo qe. ninguno con una mediana tintura de comercio sera capaz de afirmar imparcialmente qe. los míos lleguen a la mitad de los de cualquiera de dhos. Sres.; pues; como es qe. se les asigna: al primero cuatrocientos noventa: al segundo y tercero doscientos ochenta: al último doscientos cuarenta y cinco, y a mi setesientos? [...] ¿por qué principio de equidad y justicia ...? Es proporción esta Sr? [...] si es cierto lo qe. se dice qe. el tres y medio por ciento ha sido lo que se ha puesto sobre los fondos de los individuos prestamistas, pa. imponerme lo que se me ha puesto ha sido necesario calcularme un capital de veinte mil pesos [...] En la actualidad sólo hay en mi poder trescientos y esto los ofrezco [...] me será imposible entregar más $\left[\right.$ sic.$^{19}$

Si aplicamos el porcentaje aludido en la cita a las cuotas asignadas en el empréstito al que se está haciendo referencia, obtenemos que los comerciantes mencionados, que además ocupaban importantes cargos y funciones en el gobierno provincial, así como quienes encabezaban la lista de prestamistas en dicha oportunidad, aunque no fueron nombrados por Rodríguez en su reclamo, disponían de riquezas valuadas entre 10857 hasta 45714 pesos. Estos montos fueron retomados, asimismo, en investigaciones sobre las clases propietarias del Tucumán tardocolonial y posindependiente, que hablan de "fortunas muy respetables" a las comprendidas entre 20000 y 25000 pesos, mientras que los giros de comerciantes mayoristas más poderosos económicamente oscilaban entre 10000 y 35000 pesos. ${ }^{20}$

En suma, sobre la base de los datos cuali-cuantitativos hasta aquí expuestos definimos tres categorías de riqueza: el sector alto constituido por quienes disponían de más de 10000 pesos de capital, el medio comprendido entre 1000 y 9999 pesos, y el bajo formado por patrimonios menores a 1000 pesos. Por debajo de ellos se encontraba el amplio universo de pobres cuyo nulo o ínfimo patrimonio, probablemente inferior a 500 pesos, no calificaba siquiera para considerarlos como potenciales contribuyentes y que, en su gran mayoría, escaparon al registro de las fuentes tributarias. f. 20.

${ }^{19}$ Correspondencia remitida por Cayetano Rodríguez, en AHT, Administrativa, vol. 27, 1819,

${ }^{20}$ López, “Arrieros”, 1996, p. 96. 
LA DISTRIBUCIÓN DE LOS CAPITALES POR SEGMENTOS DE RIQUEZA

El padrón de contribución directa analizado registró 769 contribuyentes que en conjunto reunían un capital de 4589441.75 pesos. Los datos en el cuadro 2 indican que más de $50 \%$ de los contribuyentes se concentraba entre los sectores medios de riqueza, $32 \%$ en el bajo y sólo $14 \%$ en el nivel más alto.

La distribución de los capitales, en cambio, se aglutinaba en 67\% entre la minoría de los más ricos, $30 \%$ en los medianamente ricos y sólo un escaso $2.4 \%$ entre los menos afortunados. Esta distribución porcentual del capital mobiliario e inmobiliario en la capital de la provincia denota una importante concentración de la riqueza que se manifiesta también en un índice de Gini de 0.71 y una relación de 20-20 que confirma una concentración de $75 \%$ del capital en 20\% más rico y de sólo $1.8 \%$ en $20 \%$ más pobre (véanse cuadros $3 \mathrm{a}$ y $3 \mathrm{~b}$ ).

El análisis de los rubros en que invirtieron sus capitales cada uno de estos tres segmentos permite desentrañar, en parte, las características internas de cada una de estas agrupaciones de contribuyentes.

La gráfica 1 muestra con claridad la tendencia de los más ricos a colocar sus capitales en la propiedad inmobiliaria, en segundo término en el comercio y la manufactura, una mínima proporción en ganado y una absoluta ausencia de inversiones en actividades artesanales.

Los sectores medios parecen mantener la tendencia de los más ricos al priorizar la inversión en la propiedad de la tierra aunque manifiestan una mayor diversificación en tanto registran capital en actividades comerciales y en menor medida en las manufactureras, pero también orientaron una parte aunque reducida de sus capitales tanto a la producción de ganado como a la artesanía.

El segmento más bajo de riqueza muestra un comportamiento marcadamente diferente al de los grupos descritos con anterioridad. Sus capitales se distribuyen en su mayoría entre actividades artesanales y el comercio y en menor proporción en tierra y ganado.

Si focalizamos el análisis por rubro o actividad y el grado de participación de cada uno de los segmentos de riqueza en cada uno de ellos queda más claro aún el diseño de las estrategias de inversión en cada nivel, así como el predominio de cada segmento en las diversas actividades económicas (véase gráfica 2).

En este sentido, se advierte que la propiedad territorial, el comercio y la manufactura se encontraban bajo el predominio de los grandes capitalistas y en menor medida de los sectores medios. En la actividad ganadera se manifiesta, por el contrario, una participación más equitativa de los tres segmentos de riquezas, aunque el predominio de los más ricos se observa 


\section{CUADRO 2. DISTRIBUCIÓN DE CONTRIBUYENTES Y CAPITALES POR SEGMENTOS DE RIQUEZA. TUCUMÁN, CAPITAL, 1869}

\begin{tabular}{lccccc}
\hline Niveles & $\begin{array}{c}\text { Rangos en } \\
\text { pesos bolivianos }\end{array}$ & $\begin{array}{c}\text { Número de } \\
\text { contribuyentes }\end{array}$ & Porcentajes & $\begin{array}{c}\text { Capital } \\
\text { (pesos bolivianos) }\end{array}$ & Porcentajes \\
Bajo & $<1000$ & 247 & 32.1 & 110996.5 & 2.4 \\
Medio & 1000 a 9999 & 412 & 53.6 & 1383179 & 30.1 \\
Alto & $>10000$ & 110 & 14.3 & 3095266.25 & 67.4 \\
Total & & 769 & 100 & 4589441.75 & 99.9 \\
\hline
\end{tabular}

Fuente: elaboración propia con base en Padrón de Contribución Directa del departamento Rectoral, en AHT, Hacienda, Manuales de Contaduría, vol. 21, 1869.

también en este rubro. Las artesanías, en cambio, parecían ser exclusividad de los sectores medios y bajos cuyos capitales se encuentran representados en proporciones casi equivalentes en este rubro de actividad.

Una evidencia notoria es que más allá de las gradaciones proporcionales, los sectores compartían su participación como propietarios, comerciantes y criadores de ganado. Sin embargo, una clara frontera provenía del desarrollo o no de dos actividades concretas: artesanías y manufacturas (salvo por la dualidad de la presencia de los sectores medios en ambos rubros). Ello nos invita a detenernos, para una mayor comprensión del hecho estadístico, en estas ramas secundarias de la economía tucumana.

Como adelantamos al comienzo de este trabajo, la década de 1860 implicó una instancia de expansión económica centrada en una diversificada producción pero también en un control estratégico de mercados que permitía equilibrar las balanzas comerciales y colocar productos con cierto valor agregado. El perfil exportador de la economía tucumana, según la historiografía, daba cabida al beneficio de una variedad de actores como los azucareros, labradores, tenderos y pulperos, carreteros, hiladoras, tejedoras, costureras, criadores y artesanos..$^{21}$ Pero todos ellos eran de algún modo interceptados -a través de habilitaciones o la mercantilización- por el capital comercial, del que provenía la principal inyección en la dinámica económica provincial.

A su vez, el capital con ese origen presentaba una composición que estratificaba a distintos grupos y actuaba sobre otras actividades de diferentes formas. Efectivamente, existían jerarquizaciones internas entre co-

${ }^{21}$ Campi y Richard, “Tendencias”, 1999. 
CUADRO 3A. DISTRIBUCIÓN DE CAPITALES POR RUBRO

(TERRITORIAL, MOBILIARIO, PATENTES)

SEGÚN CATEGORÍAS DE RIQUEZA. TUCUMÁN, CAPITAL, 1869

\begin{tabular}{lcccrc}
\hline \multicolumn{7}{c}{$\begin{array}{c}\text { Rangos en } \\
\text { Categorías }\end{array}$} & pesos bolivianos & Inmobiliario & Mobiliario & Patentes & Total \\
& & & & & \\
Bajo & $<1000$ & 22312.5 & 20334 & 68350 & 110996.5 \\
Medio & 1000 a 9999 & 847700 & 41328 & 494651 & 1383679 \\
Alto & $>10000$ & 1775772.5 & 51494 & 1268000 & 3095266.5 \\
Total & & 2645785 & 113156 & 1831001 & 4589942
\end{tabular}

Fuente: elaboración propia con base en Padrón de Contribución Directa del departamento Rectoral, en AHT, Hacienda, Manuales de Contaduría, vol. 21, 1869.

\section{CUADRO 3B. DISTRIBUCIÓN DE CAPITALES POR RUBRO DE PATENTES SEGÚN CATEGORÍAS DE RIQUEZA. TUCUMÁN, CAPITAL, 1869}

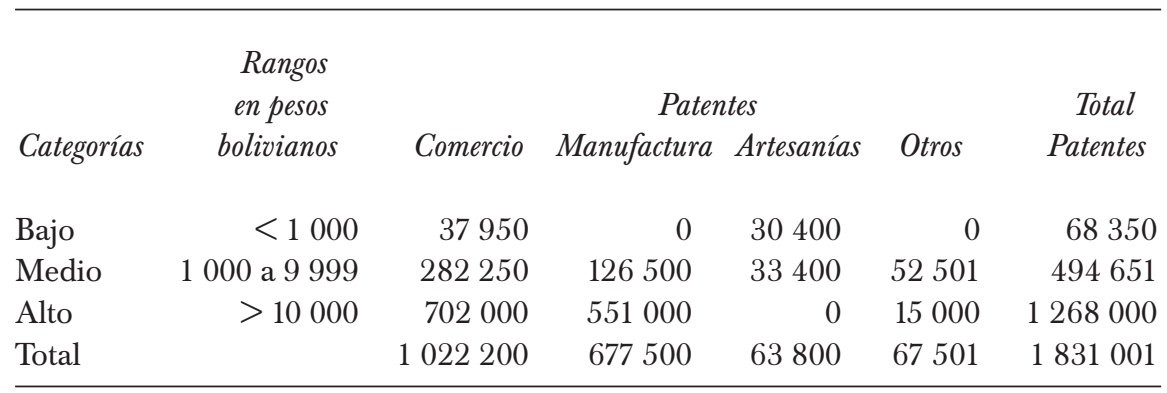

Fuente: elaboración propia con base en Padrón de Contribución Directa del departamento Rectoral, en AHT, Hacienda, Manuales de Contaduría, vol. 21, 1869.

merciantes exportadores, importadores, tenderos y pulperos, ${ }^{22}$ así como entre las firmas o propietarios de los productos exportados, los troperos y los despachantes. ${ }^{23}$ En cuanto al sector secundario y la asociación con el capital comercial, tal vez era el estadio de protoindustrialización o de plena fusión capital comercial y capital industrial el que determinaba la fragmentación entre artesanos y manufactureros.

\footnotetext{
${ }^{22}$ Parolo, Ni, 2008.

${ }^{23}$ Campi, "Aproximación”, 2000-2001.
} 
GRÁFICA 1. DISTRIBUCIÓN DE CAPITALES POR RUBRO

EN CADA UNA DE LAS CATEGORÍAS DE RIQUEZA.

TUCUMÁN, CAPITAL, 1869

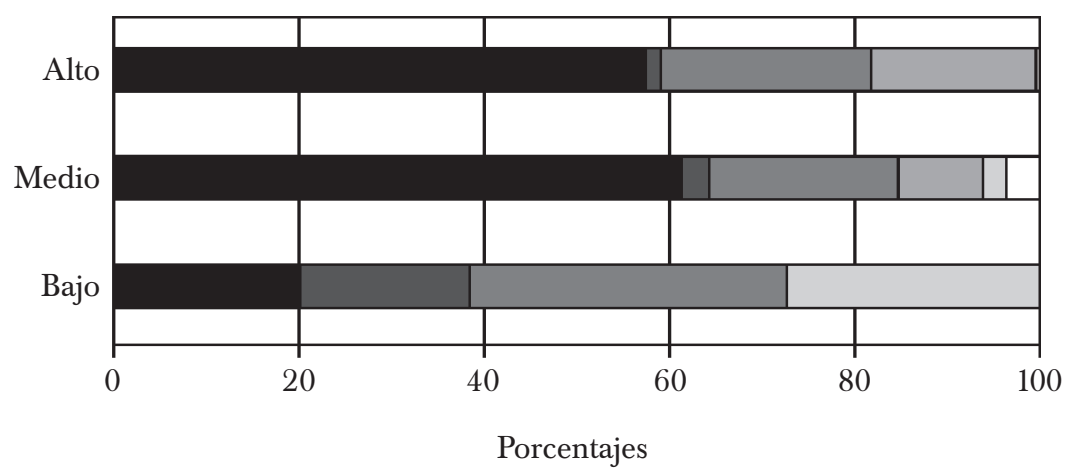

Territorial $\square$ Ganado $\square$ Comercio $\square$ Manufactura $\square$ Artesanías $\square$ Otros

Fuente: véanse cuadros $3 \mathrm{a}$ y $3 \mathrm{~b}$.

GRÁFICA 2. DISTRIBUCIÓN DE LOS CAPITALES POR CATEGORÍA DE RIQUEZA EN LAS DIFERENTES ACTIVIDADES ECONÓMICAS. TUCUMÁN, CAPITAL, 1869

Porcentajes

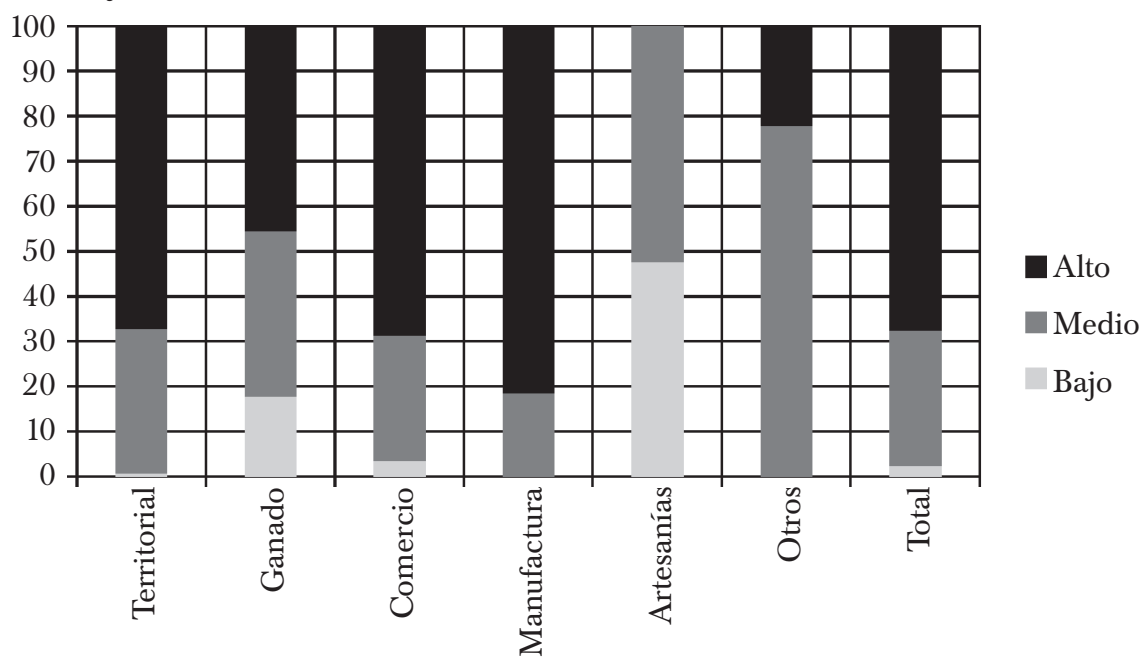

Fuente: véanse cuadros $3 \mathrm{a}$ y $3 \mathrm{~b}$. 
Los talleres artesanales tenían tradición colonial y englobaban distintas actividades manuales como la herrería, carpintería, sastrería, etc., las que se agrupaban en gremios por oficios. Esta organización gremial provocaba una secuenciación interna de peones, oficiales, aprendices, maestros y maestros mayores de obra. Si bien sus productos participaban fundamentalmente del mercado local, bajo el sistema de encargo, también podían captar otras plazas con la lógica intermediación de los comerciantes. Hasta donde se ha indagado, los artesanos tucumanos del siglo XIX no gozaban de una posición económica holgada ni sólida, ni mayor prestigio social, aunque era factible cambios de posiciones en el espacio social por procesos de movilidad horizontal (lo usual fue que devinieran pulperos como máximo rango) y vertical (de peón a maestro). ${ }^{24}$

Lo que no se ha comprobado son otras transferencias intersectoriales, como la inversión directa de comerciantes en la montura de talleres artesanales. Esa dirección del capital comercial, por el contrario, fue paulatinamente más recurrente y creciente en distintas manufacturas. Los principales rubros que podemos asociar a esta categoría son la producción de tabacos, cueros, azúcar y aguardientes. En cada caso su producción requería de escalas de inversiones diferentes tanto para fundar los establecimientos de tratamiento y producción, con mínimas tecnologías, como para la contratación de mano de obra. Por otra parte, los bienes elaborados en esas "fábricas" (o protoindustrias) constituyeron aunque cíclicamente los principales rubros de la canasta de exportaciones de la provincia.

Para los ingenios azucareros la participación en la fase productiva del capital comercial selló su importancia en la década de 1860, principalmente por un salto de escala. Las investigaciones sobre esta etapa formativa de la agroindustria revelan que fue más intenso de lo que se suponía el número de actores que apostaron a la instalación de rudimentarios ingenios y destilerías de aguardientes, además de la fabricación campesina artesanal de mieles y dulces. Pero el prototipo del circuito de inversión de los sectores más concentrados del comercio tucumano fue la adquisición de quintas semiurbanas o fincas del área capitalina provincial, unidades productivas que al comienzo mostraban una alta diversificación, de un fundo relativamente pequeño, en el que se reunía las plantaciones de caña y la fabricación de azúcar y aguardientes con la instalación de trapiches y alambiques. Pero ya para la década de 1860 la rentabilidad de la caña y la producción de sus derivados de mayor mercantilización fue fundando la especialización hasta quedar registrados e identificados nominalmente como "establecimientos azucareros". ${ }^{25}$

\footnotetext{
${ }^{24}$ Parolo, Ni, 2008, pp. 102-111.

${ }^{25}$ Campi, "Espacio", 2002.
} 
Las curtiembres eran otras de las principales manufacturas tucumanas del siglo XIX pese a que fue justamente desde la década de 1860 y el posterior afianzamiento y reinado del azúcar el momento que marcó el inicio de su declive. Pero hasta entonces, y muy por encima de los derivados de la caña de azúcar, los cueros y suelas eran los principales rubros de la exportación tucumana. Distintos signos nos revelan una dinámica actividad que crecía en sus niveles de mercantilización, en el número de establecimiento y en la tecnificación. Esa favorable evolución queda manifestada en la mirada de Burmeister, quien recorrió la provincia a mediados del siglo XIX:

En Tucumán se trabaja mucho la curtiduría [...] Al principio se curtían sólo cueros amarillos ordinarios que se usaban para arreo de los caballos, principalmente para monturas y para calzado ordinario; ahora se comienza a fabricar cuero marroquí de color, que se utiliza para adornar los arreos. También se manda ahora a Buenos Aires cueros medios curtidos en lugar de los sin curtir que se mandaban siempre antes, pero que no podían competir en sus precios con los cueros de las provincias más cercanas, a causa del elevado costo del transporte. Por eso se establecieron las curtiembres en Tucumán mismo. ${ }^{26}$

A comienzos del siglo XIX las modalidades de producción eran básicamente dos. Las de mayor escala, representadas en las curtiembres instaladas por sus propietarios en las estancias y haciendas. Otra eran las curtidurías pobres del área capitalina que funcionaban como industrias a domicilio. La participación del capital comercial se presentaba entonces por las operaciones de habilitación a los hacendados, el acopio de cueros para curtir, la provisión de materias primas a los curtidores pobres y el mayor control que tenían en la esfera de la circulación mercantil de este producto. ${ }^{27}$ No obstante, y asociada a la inmigración vasca francesa de la primera mitad del siglo XIX, las empresas del cuero que evocaba Burmeister sugieren las escalas de una mayor fusión y participación productiva del capital comercial, aluden a establecimientos de mayor envergadura, aunque menos integrados que los azucareros pues las fábricas de cueros tinturados con tanino y montadas en las inmediaciones al oeste de la ciudad capital $^{28}$ mantuvieron la labor de acopio de cueros brutos de los criadores, especializándose en el refinamiento del cuero.

${ }^{26}$ Burmeister, Descripción, 1916, p. 45.

${ }^{27}$ Zamora, "Abasto", 2011.

${ }^{28}$ El tanino se obtenía de un árbol silvestre y, al comienzo, abundante en Tucumán (el cebil), pero su utilización como producto tintóreo de cueros provocó una tala indiscriminada de los bosques de cebil cercanos al epicentro curtidor, la zona del Manantial de Marlopa, que era abundante en otro recurso prioritario de estas empresas, el agua. Según Burmeister, este hecho fue en parte responsable de la paulatina pérdida de rentabilidad de la curtiduría, pues la escasez del tanino 


\section{EXPANSIÓN ECONÓMICA, NIVELES DE RIQUEZA Y ESTRUCTURA SOCIOOCUPACIONAL}

En la década de 1860 dominaba un contexto favorable a la acumulación de capitales, pero también de quiebres en sectores económicos tradicionales, que en definitiva significó una coyuntura de redefinición y de movilidad social. ¿Cómo repercutió la misma en el escenario social capitalino tucumano? Sin duda es una pregunta ambiciosa que intenta arrojar ciertas luces sobre las jerarquías sociales tucumanas en la etapa formativa del azúcar. Si bien no podemos ofrecer visiones definidas, procuramos profundizar la clasificación de los escalafones de las riquezas sectoriales existentes mediante un estudio que coteja las fuentes fiscales, con fuentes demográficas de la época. Concretamente el procedimiento ha sido compulsar nominativamente a los contribuyentes de los padrones de la contribución directa del departamento capital con, en primer lugar, una muestra de los agentes mayores de quince años consignados en las cédulas censales del censo de población de 1869 y, en segundo lugar, con los propietarios de establecimientos azucareros que nomina Arsenio Granillo para 1872.

Apuntamos a clarificar la graduación de la riqueza de esta sociedad en su vinculación con las implicancias socioocupacionales de la coyuntura analizada, apelando a las ventajas que da el seguimiento de los nombres propios. Si bien, como veremos, este análisis corrobora gran parte de las ideas ya advertidas anteriormente, ofrece algunos matices y, sobre todo, permite visualizar a los sectores desprovistos de riqueza, según las escalas indicadas. De la muestra obtenida logramos detectar por el cruce de información con las cédulas censales a 167 de los 769 contribuyentes, a los que les corresponde $30 \%$ de la riqueza global del departamento Capital (véase cuadro 4). Advertimos que en términos absolutos la frecuencia con que los comerciantes detectados en las cédulas censales son a la vez sujetos fiscales en los registros de la contribución directa, así como los capitales que comprende a ese conjunto, se desatacan ampliamente sobre el resto de las categorías ocupacionales consignadas. Ese sector involucraba a 37\% de todos las personas identificadas en cédulas y padrones fiscales y a $57.7 \%$ de los capitales implicados. Muy por debajo, en porcentajes cercanos a 5\%, se detectó la presencia en los registros de contribución directa a distintas personas autodefinidas en el censo de 1869 como abogados, labradores o agricultores, zapateros, carpinteros y un grupo de individuos sin ocupa-

obligó ampliar el área de explotación del cebil encareciendo el costo de transporte de las cortezas de este árbol, que primero se triturara en molinos de grandes piedras movidos por caballos, luego se concentraba en recipientes artificiales que se conectaban a los arroyos, donde se disponían los cueros para su teñido. Burmeister, Descripción, 1916, p. 46. 


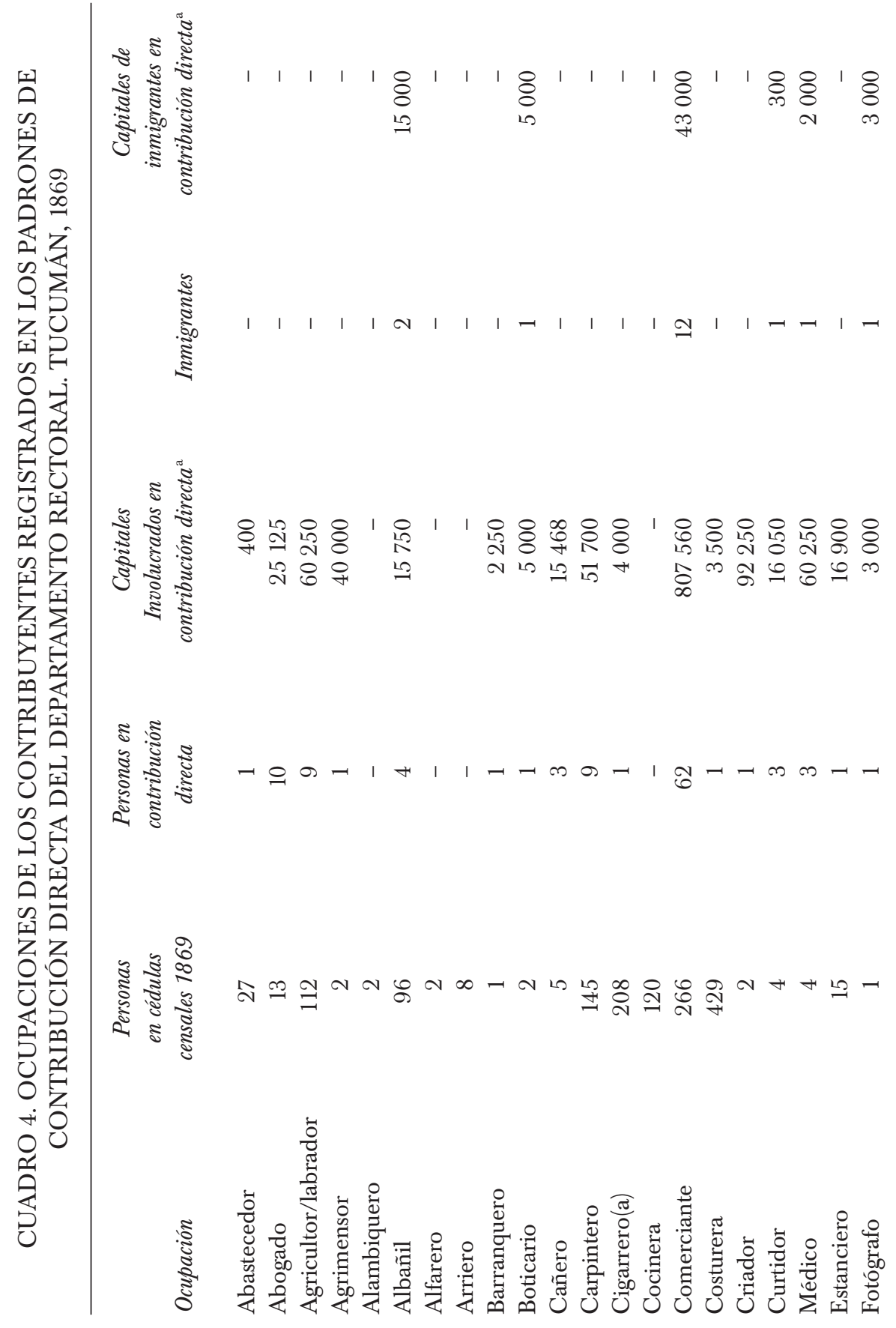



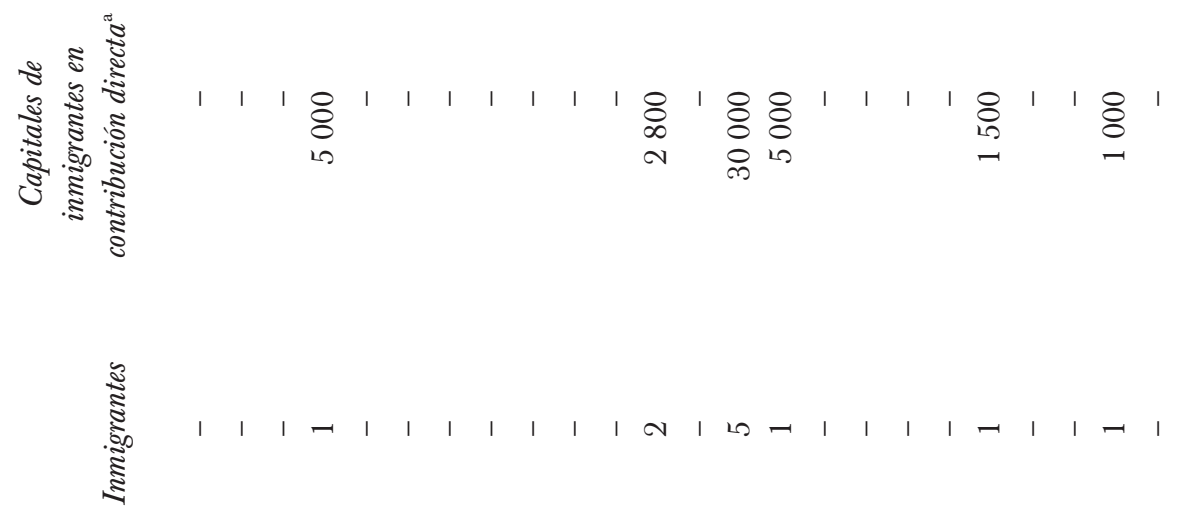

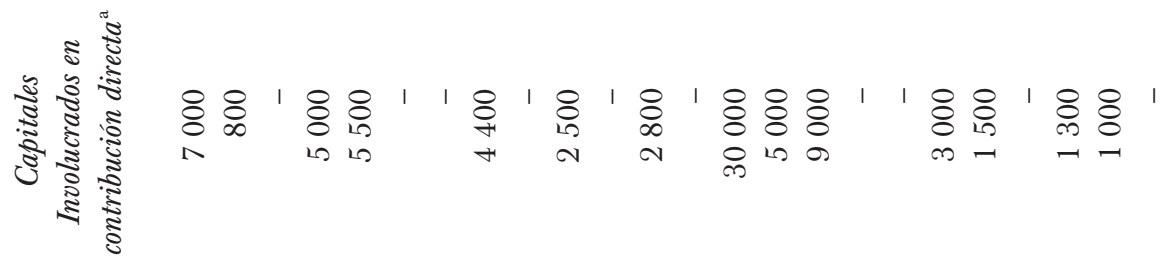

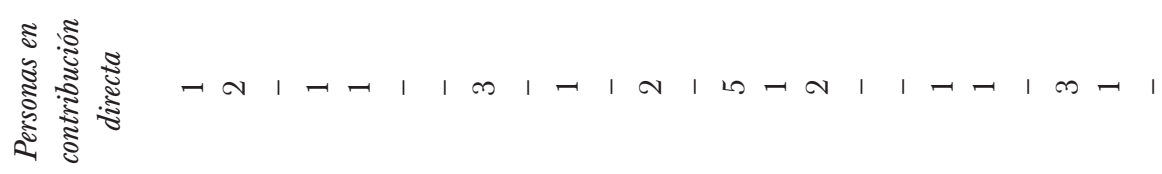

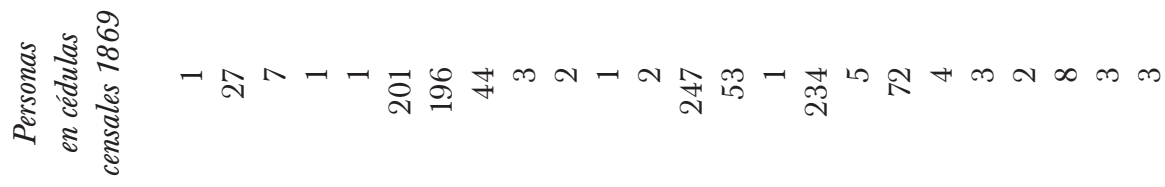

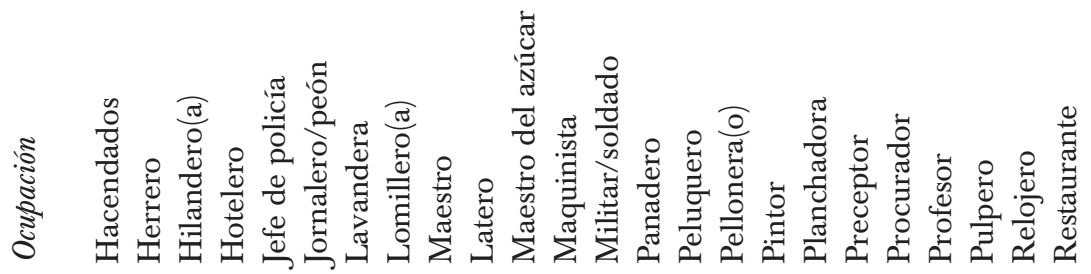




$$
\begin{aligned}
& \begin{array}{lllllllll}
1 & 1 & 1 & 1 & 1 & 1 & 1 & 1 & 1 \\
\hdashline & 0 \\
0 \\
0
\end{array} \\
& \text { §̊ํํ } \\
& \wedge \sim \infty \quad 0=\infty \\
& \text { - }
\end{aligned}
$$

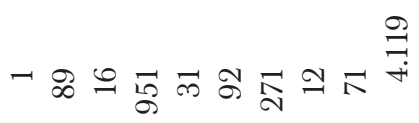

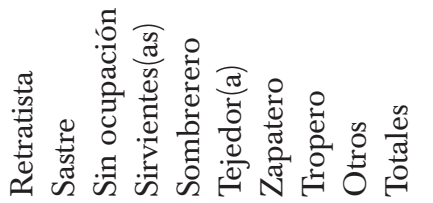

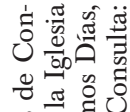

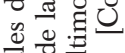

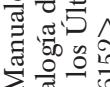

$$
\begin{aligned}
& \sum \frac{0}{\pi} 0 \\
& \text { 羟 क } \\
& \text { 讨 } \\
& \text { 퐁 n } \\
& \text { 至气 } \\
& \text { 过艺管 }
\end{aligned}
$$

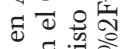

$$
\begin{aligned}
& \text { तี व }
\end{aligned}
$$

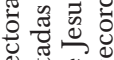

$$
\begin{aligned}
& \text { 幽 } \\
& \text { 윰 } \frac{\pi}{0} \text { के } \\
& \text { व } 0 \\
& \text { 교에 }
\end{aligned}
$$

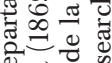

$$
\begin{aligned}
& \text { 푼 } \\
& \text { 웡 }
\end{aligned}
$$

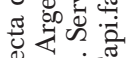

$$
\begin{aligned}
& \text { 엄 던 }
\end{aligned}
$$

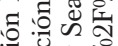

$$
\begin{aligned}
& \text { 정 } \\
& \text { है 을 }
\end{aligned}
$$

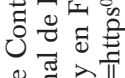

$$
\begin{aligned}
& \text { ช 종 } \lambda .11 \\
& \text { 들 苞 } \\
& \text { क्ष }
\end{aligned}
$$

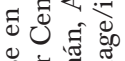

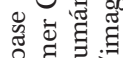

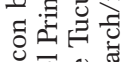

$$
\begin{aligned}
& \text { 过艺 } \\
& \text { के चै के के } \\
& \text { 플 } \\
& \text { 串记苟 } \\
& \text { ข่ }
\end{aligned}
$$

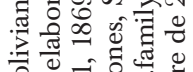

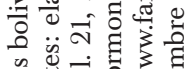

$$
\begin{aligned}
& \text { की }
\end{aligned}
$$

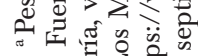

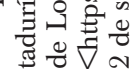


ción, los que en conjunto apenas reunían una cuarta parte de los valores correspondientes a los comerciantes y 15\% de la suma total de capitales consignados en el cuadro 4.

Sin embargo, en términos relativos al total de individuos por ocupación detectados en el censo, ciertos oficios menos típicos ofrecen la máxima concurrencia entre categoría ocupacional censal y sujetos de gravamen fiscal, como, por ejemplo, maquinista, peluquero, hotelero, fotógrafo, retratista. En cambio, los comerciantes contribuyentes son sólo 23\% de los registrados con esa categoría en el censo. Situaciones más extremas presenta el caso de sectores artesanales como la zapatería y la carpintería, donde sólo nueve de los 271 zapateros y nueve de los 145 carpinteros conformaban el universo de actores con un mínimo de riqueza gravada con fines impositivos. Igualmente, los capitales relativos al número de contribuyentes por ocupación arrojan un promedio que modifica el esquema de los rangos considerando los capitales absolutos. En este sentido resulta que criadores (con 92250 pesos promedio), troperos (con 55661 pesos promedio), un agrimensor (con 40000 pesos), médicos (en promedio 20083 pesos) y un estanciero (con 16900 pesos) presentan riquezas promedio muy por encima de los comerciantes, a quienes les corresponde 13025 pesos.

Ahora bien, si afinamos el análisis por niveles de riqueza, advertimos que las tendencias observadas en la distribución de los capitales por actividad económica presentan un marcado correlato con la distribución de las ocupaciones de los contribuyentes entre los tres segmentos en que clasificamos los niveles de riqueza. Ello obedece en gran medida a que hay una elevada coincidencia entre la ocupación declarada en el censo con el tipo de carga fiscal que se paga. El cuadro 5 resume los datos obtenidos del cruce de información procedente de los listados de contribución directa de Capital y de las cédulas del censo de 1869 por segmento de riqueza.

Tanto en la categoría de comerciante como entre productores agropecuarios se advierte la participación de los tres segmentos de riqueza examinados. En efecto, dichas ocupaciones no determinaban en sí mismas un posicionamiento social. Las categorías ocupacionales analizadas no expresaban, por lo tanto, cortes horizontales dentro de una jerarquía de posiciones sociales y económicas, sino agrupamientos y delimitaciones de tipo vertical con sus propios rangos internos (véase gráfica 3).

Es decir, tanto entre los criadores como entre los labradores se advierte una composición interna diversificada en la que coexistían, bajo la misma denominación, propietarios y arrendatarios, algunos vinculados al comercio y al transporte, los que disponían de personal dependiente (peones, inquilinos, arrendatarios o agregados). Por otro lado, encontramos productores cuya relación con la tierra era también diversa, predominando los no propietarios que utilizaban mano de obra doméstica. Además, 
Am. Lat. Hist. Econ., año 21, núm. 2, mayo-agosto, 2014, pp. 199-232

\section{CUADRO 5. OCUPACIONES DE LOS CONTRIBUYENTES SEGÚN SEGMENTOS DE RIQUEZA. TUCUMÁN RECTORAL, 1869}

\begin{tabular}{lrrrr} 
Ocupaciones & \multicolumn{3}{c}{ Segmentos } \\
& Bajo & Medio & Alto & Total \\
Comerciante $^{\mathrm{a}}$ & 16 & 38 & 24 & 78 \\
Artesano $^{\mathrm{b}}$ & 18 & 19 & 2 & 39 \\
Productor agropecuario $^{\mathrm{c}}$ & 2 & 7 & 8 & 17 \\
Profesionales $^{\mathrm{d}}$ & 0 & 13 & 2 & 15 \\
Otros $^{\mathrm{e}}$ & 3 & 21 & 2 & 26 \\
Total & 39 & 98 & 38 & 175
\end{tabular}

a Tendero, pulpero, tropero, hotelero, panadero, botiquero.

${ }^{\mathrm{b}}$ Carpintero, zapatero, herrero, relojero, sastre, latero, pellonero, lomillero, cigarrero, albañil.

${ }^{\mathrm{c}}$ Labrador, criador, hacendado, terrateniente, agricultor, cañero, estanciero.

${ }^{\mathrm{d}}$ Abogado, médico, procurador.

${ }^{e}$ Maquinista, costurera, jefe de policía, portero, retratista, sin ocupación.

Fuentes: elaboración propia con base en Padrón de Contribución Directa del departamento Rectoral, en AHT, Hacienda, Manuales de Contaduría, vol. 21, 1869, y Cédulas del Primer Censo Nacional de Población de Argentina (1869), en Centro de Genealogía de la Iglesia de los Mormones, San Miguel de Tucumán, Argentina.

\section{GRÁFICA 3. OCUPACIONES DE LOS CONTRIBUYENTES SEGÚN SEGMENTOS DE RIQUEZA}

Porcentajes

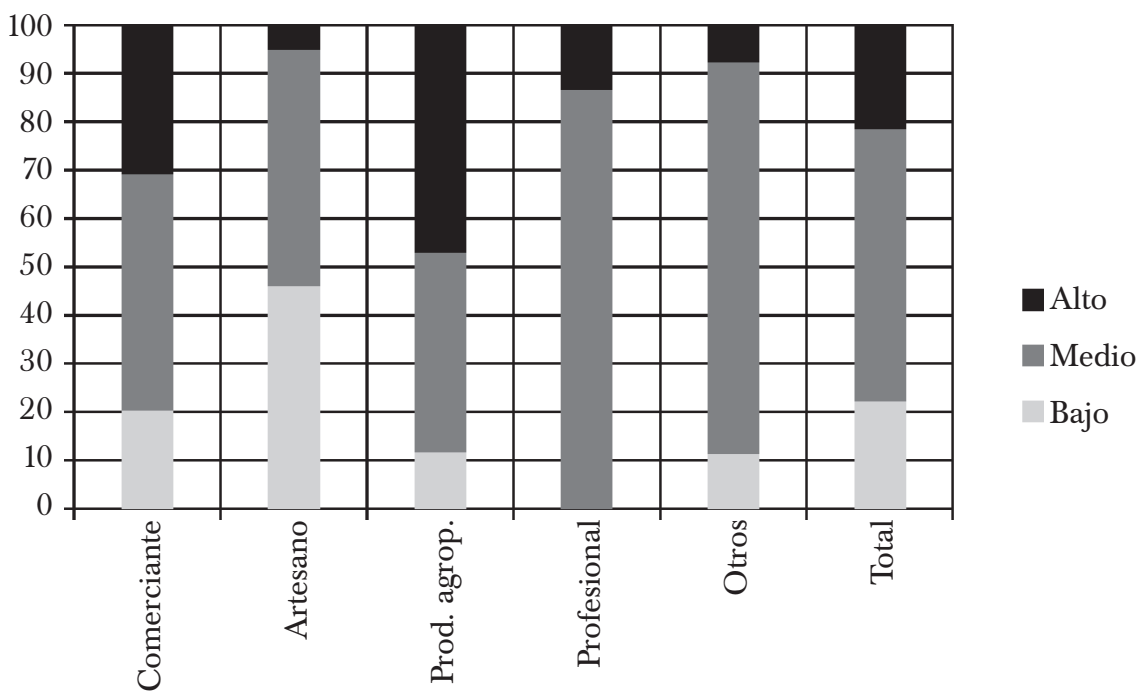

Fuente: véase cuadro 5 . 
existen evidencias de la combinación de las actividades agrícolas y ganaderas complementadas, incluso, con la venta de la fuerza de trabajo. Los principales productores rurales parecían residir mayormente en el ámbito urbano. Del mismo modo, los sectores más pudientes dentro de los productores agropecuarios (hacendados y agricultores) desarrollaban sus actividades productivas junto con las de comercialización y transporte de mercancías. ${ }^{29}$

Algo similar sucedía entre los comerciantes. Bajo esta misma categoría se aglutinaban diferentes rangos o esferas dentro de la actividad mercantil. Se encontraban aquellos que abrían tiendas destinadas a la importación y exportación de bienes, otros que centraron sus negocios en la venta al menudeo y establecían pulperías, almacenes o boliches y quienes se encargaban del transporte de mercaderías (troperos, fleteros o carreteros). De este modo, la capacidad de acumulación de capital y de inversión en otras actividades de alta rentabilidad (como en la producción de azúcar o la compra de tierras) y, por ende, sus niveles de riqueza y posición de prestigio diferían entre unos y otros. ${ }^{30}$

Por otra parte, la actividad azucarera participaba todavía con iguales o menores grados de implicancia en el conjunto de exportaciones tucumanas en la década de 1860, pero ya era la principal promesa de desarrollo y fuente de enriquecimiento según las anotaciones sobre inversión inicial y beneficios entre los estadistas de la época. En 1872 Granillo apuntaba la existencia de 44 ingenios, 38 con sede en el departamento Capital, de cuyos propietarios hemos identificado en los padrones de contribución directa analizados a 22 de los mismos (véase cuadro 6). Este universo de actores en forma conjunta controlaba $15 \%$ del total de los capitales por toda la riqueza imponible de esta porción geográfica, a su vez representaban $21 \%$ de los valores totales del sector alto de la sociedad. De hecho, con un contorno socioocupacional heterogéneo (fueron registrados en el censo de 1869 como comerciante, cañero, abogado, labrador y médico) los industriales azucareros en esta época eran en su mayor parte miembros de ese segmento social tucumano. En cuanto a las excepciones observadas, Zenón Corro y Fidel García parecían ser sujetos que concentraban sus inversiones y actividades únicamente en el sector industrial, disminuyendo de este modo la captación de riqueza desde otros ángulos económicos. Mientras que los otros casos (con capitales en la franja correspondiente a los sectores medios), todavía en 1869 (que es nuestro año de registro de las riquezas valuadas para la contribución directa) no habían participado de las posibles y seguras ganancias que la fabricación de azúcar y aguardiente

\footnotetext{
${ }^{29}$ Parolo, "Criadores", 2000.

${ }^{30}$ Parolo, "Actores", 2005.
} 


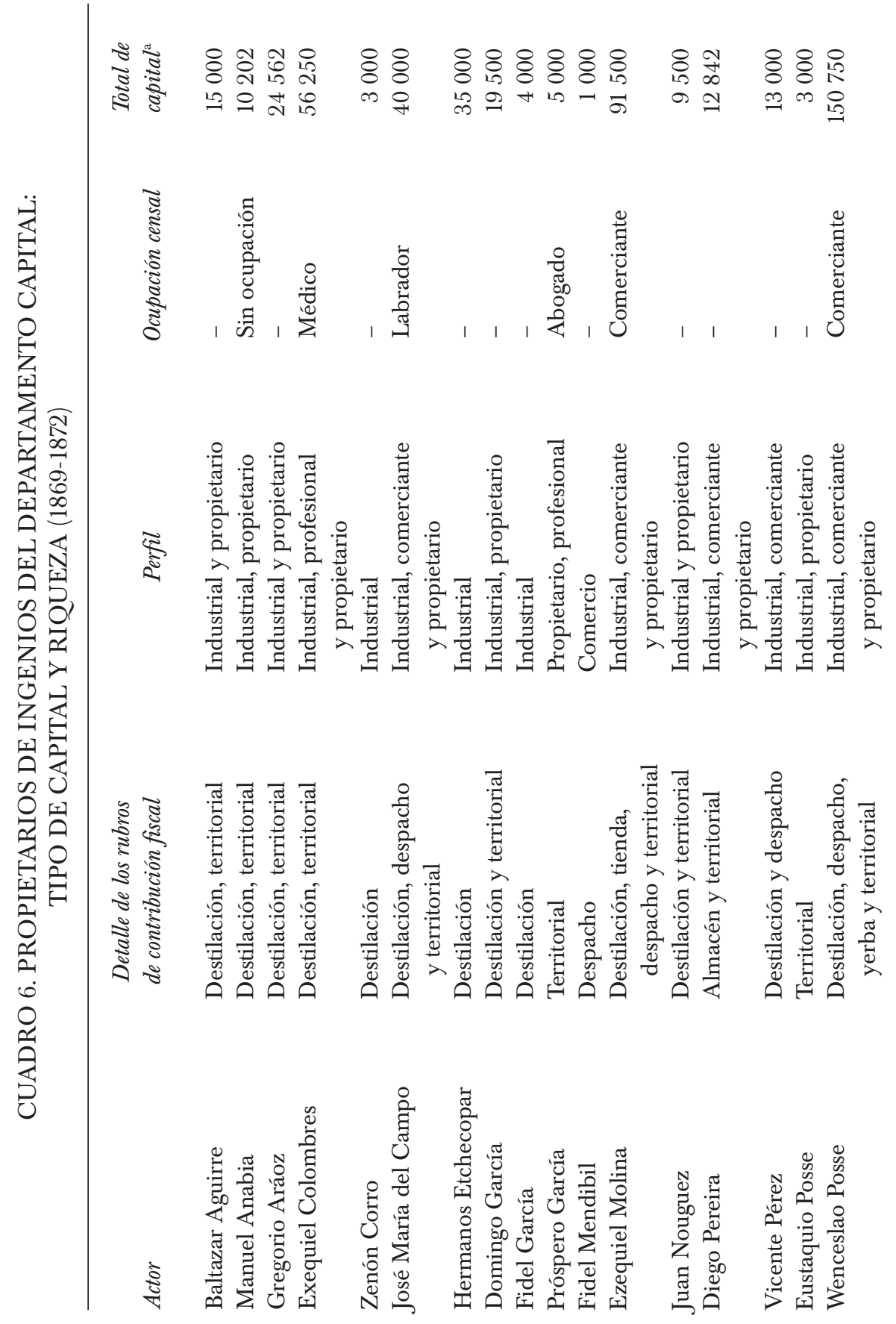




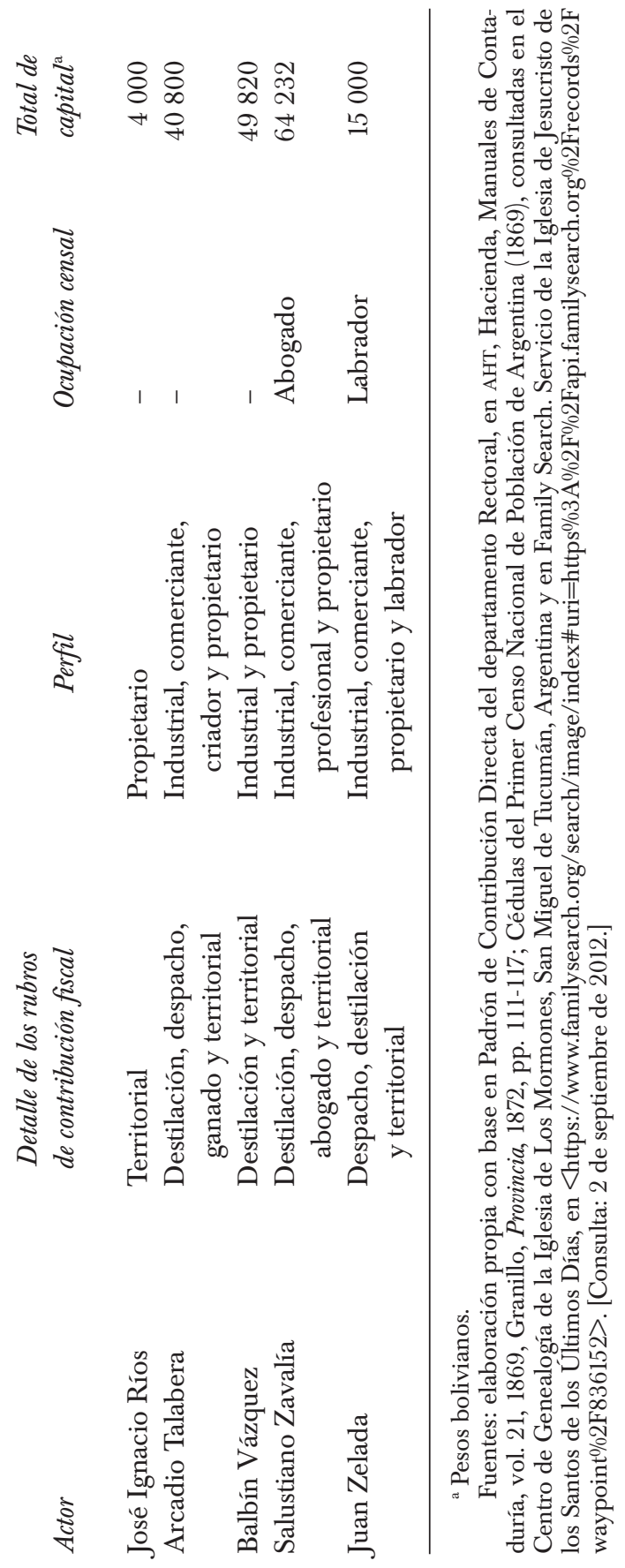


procuraban, pues recién se incluyeron en ese ámbito en la nómina proporcionada por Granillo para 1872.

Los artesanos se ubicaban principalmente entre los sectores bajos y medios de riqueza. Cabe aclarar que el grueso de los contribuyentes que pagaron patentes por talleres artesanales $(75.5 \%)$ se concentran en el rango de riqueza que va de 500 a 5000 pesos de capital, es decir, la franja de mayor capital dentro del segmento bajo de riqueza (34.4\%) y la franja de menor capital dentro del nivel medio de riqueza (41.1\%). Entre los artesanos también se evidenciaba una suerte de estratificación interna según las capacidades de acumulación y el posicionamiento social, en estrecha vinculación con su calidad de aprendices, oficiales o maestros. Más allá de estas diferencias internas, ni unos ni otros pertenecían a la clase política y económicamente dominante.

Por último, los profesionales aparecen casi en su totalidad registrados entre los sectores medios de riqueza. Su capacidad de acumulación, empero, no parece haber estado reducida al ejercicio de su actividad profesional en tanto figuran pagando, además de sus patentes por dicho ejercicio, por propiedades inmobiliarias y, uno de ellos, por un almacén. Si focalizamos el análisis de las ocupaciones por segmento las tendencias antes apuntadas cobran más relevancia aún (véase gráfica 4).

El cruce de datos entre las fuentes fiscales y demográficas confirma, entonces, el predominio de las actividades mercantiles en los segmentos medio y alto. Entre los menos ricos, empero, las profesiones artesanales superan ligeramente a las vinculadas al comercio. Por otra parte, se ratifica en los sectores medios una mayor diversificación económica -traducida en una marcada multiplicidad ocupacional- y la concentración de profesionales y artesanos. Del mismo modo que cuando examinamos los rubros de actividades por segmentos (véase gráfica 1), el análisis de la distribución de las ocupaciones demuestra una vez más que los más ricos asentaron sus patrimonios en el ejercicio del comercio mayorista y de larga distancia (tenderos, troperos, comerciantes) y en la propiedad inmobiliaria, en tanto que los que figuran como cañeros y criadores pagaron altas cuotas por contribución territorial. ${ }^{31}$

${ }^{31} \mathrm{El}$ panorama que arrojaron las fuentes fiscales hasta aquí analizadas concuerda, asimismo, con el obtenido por investigaciones realizadas a partir de otros fondos documentales. En este sentido, es notable la correlación entre los resultados obtenidos por Fandos y Fernández Murga a partir del análisis de las operaciones de compraventa de tierras en Tucumán a mediados del siglo XIX con los que aquí presentamos. El análisis socioprofesional de los agentes actuantes en estas operaciones les permitió identificar con patrimonios inmobiliarios superiores a 24000 pesos a los grandes comerciantes mayoristas de larga distancia; en un segundo nivel (entre los $8000 \mathrm{y}$ 18000 pesos) a carreteros (troperos o fleteros y a comerciantes de menor rango (corta y mediana distancia) y en el último de ellos (con inmuebles inferiores a 4000 pesos) predominantemente a pulperos, en Fandos y Fernández, "Sector", 2000-2001. En esta misma línea, pero a partir del 


\section{GRÁFICA 4. COMPOSICIÓN OCUPACIONAL EN CADA SEGMENTO DE RIQUEZA}

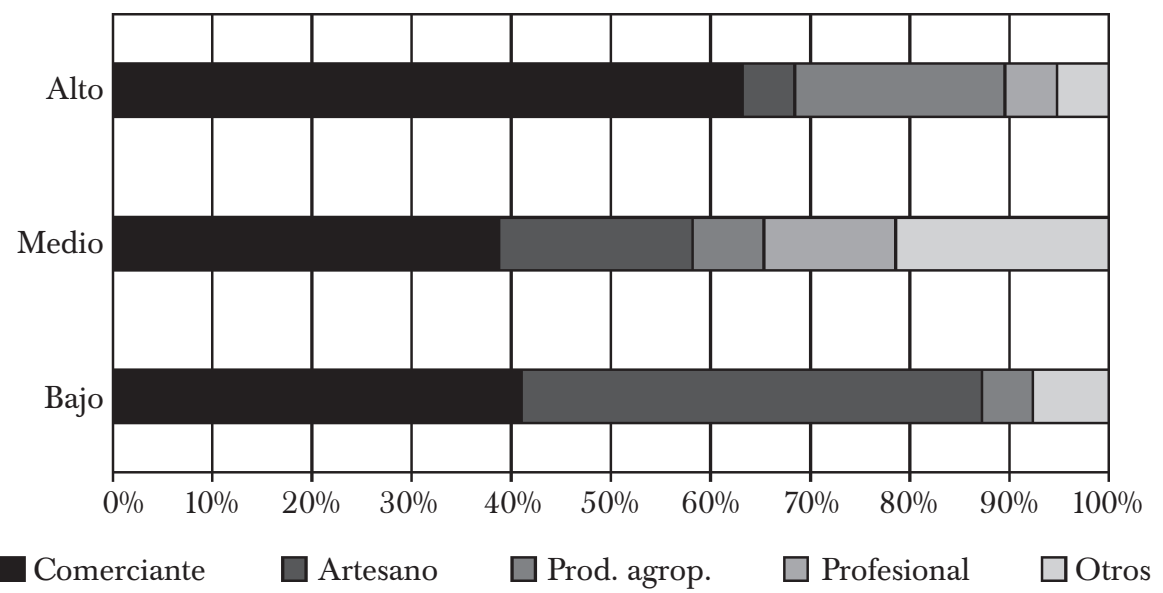

Fuente: véase cuadro 5.

\section{CONSIDERACIONES FINALES}

El análisis de la distribución de capitales entre los diferentes rubros económicos, desagregados por segmentos de riqueza y cruzados con la estructura socioocupacional -realizado en este trabajo-, así como las conclusiones de investigaciones similares sobre distribución de la riqueza a partir de otras fuentes documentales que venimos citando, no dejan duda sobre la importancia que tuvo el capital comercial en Tucumán en la etapa formativa de la agroindustria azucarera. Sobre la brecha relativa de este sector de los grandes capitalistas en el conjunto de la sociedad provinciana, basta con indicar que ellos controlaban alrededor de 50\% de toda la riqueza privada tucumana medible en la década de 1860, lo que también revela la capacidad de concentración y de acumulación que había logrado.

análisis de inventarios post mortem entre 1869 y 1884, Beatriz Álvarez identifica cinco niveles de riqueza a los que asocia con las ocupaciones de los testantes. Determina así un primer segmento "muy alto" en el que incluye abogados, hacendados, propietarios; uno "alto" conformado por agricultores, cañero, comerciante, criador, músico, platero; uno "medio" que incluye abastecedor, aguatero, carpintero, carrero, curtidor, herrero, labrador; el "bajo" representado por un zapatero y, finalmente, el "muy bajo" que aglutinaba costureras, peones, jornaleros, velloneras y sirvientes, en Álvarez, "Desigualdad”, 2011. 
Efectivamente, el mejor posicionamiento de los sectores comerciantes mayoristas y de los exportadores en el esquema que hemos delineado de la estratificación social según la riqueza, resulta concordante con el perfil trazado sobre la burguesía tucumana. El grueso de ese sector combinaba hacia la década de 1860 el comercio de larga distancia, por exportación o reexportación, a veces con tropas propias de carretas, otras con propiedad de barracas (depósitos de frutos del país), producción de azúcares y aguardientes; también en algunos casos eran criadores de ganado, propietarios de predios rurales y de las primeras casas de azotea de uno y dos cuerpos en la ciudad de Tucumán (que comenzaron a contrastar con la mayoritaria presencia de edificios con techo de teja o de paja), a los que algunos sumaban también miembros familiares con alguna cualificación profesional (médico, abogado, militar) y la propiedad de curtiembres. Se trata entonces de una burguesía de origen comercial, pero altamente diversificada en este estadio del capitalismo tucumano, con amplia participación en las actividades que le brindaban fuentes seguras de acumulación de riqueza, salvo una en concreto: las artesanías. Sobre ese perfil la interpelación historiográfica nos invita a ponderar dos cuestiones centrales como colofón de nuestro análisis.

En primer lugar, la ductilidad de la burguesía tucumana cuenta con suficiente aval empírico. Desde su formación en el comercio de importación, exportación, reexportación y el mercado local, a fines de la etapa colonial, fue reinvirtiendo sus capitales en tierras, propiedades urbanas y diferentes negocios. Para mediados del siglo XIX acoplaba varias actividades, como la participación directa en las principales manufacturas tucumanas. De manera que las fotografías que nos brindan las fuentes fiscales trabajadas para medir y componer sus riquezas en los años de 1860 nos revelan la faceta de diversificación de estos actores. Esta falta de especialización en el sector ha sido interpretada como un tipo de conducta empresaria orientada a minimizar riesgos porque en la época ninguna actividad ofrecía más altos márgenes de beneficios por sí misma. ${ }^{32}$ Esas condiciones comenzaron a cambiar al promediar la década de 1860 por una combinación de factores: la conquista de la pax política, el declive de industrias tradicionales desamparadas en los mercados y provisión de créditos y una institucionalidad favorable producto del fortalecimiento del Estado. ${ }^{33}$

En segundo lugar, antes de la especialización azucarera, la inversión directa en variadas actividades por parte de la burguesía comercial tenía una frontera definida, pues del análisis resulta central su vinculación a las "manufacturas" y su ausencia en las "artesanías". No obstante, las tareas de inter-

\footnotetext{
${ }^{32}$ Campi, “Aproximación”, 2000-2001, p. 177.

${ }^{33}$ Sánchez, "Industria”, 2005, pp. 150-151.
} 
mediación que ejercía este diversificado y rico sector mercantil precisamente sobre las artesanías, cuentan con claros indicios: como en el acopio de cueros, tabaco y cigarros para la exportación, y hasta iniciativas de modernización tecnológica en la tradicional industria textil tucumana. ${ }^{34}$ Esa distancia del sector artesanal que detentaban los principales capitalistas de Tucumán era también social, porque precisamente los artesanos se ubicaban en los límites inversos de la jerarquización según las riquezas en esta sociedad.

Artesanías y manufacturas desmembraban sectores sociales en los rangos de riqueza analizados. Esa diferencia social connotaba disímiles actividades económicas. Las artesanías englobaban un amplio grupo de oficios, a su vez agremiados y jerarquizados internamente. Por el contrario, las escalas de actividades manufactureras eran diversas. Algunas adoptaban un perfil protoindustrial, pero la fracción manufacturera más importante que se visualiza entre las principales fortunas capitalinas del Tucumán de la década de 1860 era la que ya fusionaba capital comercial con la propia esfera de la producción.

Asimismo, pese a la participación destacada de las artesanías en la provisión de ingresos a la provincia por exportación, el propio sector artesanal ocupaba los rangos medio y bajo en la estructura social según la composición de la riqueza. Al respecto hay que decir que además de componer una importante porción del segmento de menor riqueza, el grueso de los artesanos ni siquiera reunía el mínimo de capital sujeto a gravamen impositivo. Ello queda claramente evidenciado en el escaso porcentaje de carpinteros, pelloneros, zapateros, talabarteros, lomilleros, sastres, sombrereros que fueron identificados como contribuyentes en el cruce de las fuentes fiscales y demográficas (véase cuadro 4). Entendemos que si bien la actividad artesanal apenas permitía superar el nivel de subsistencia también constituía una vía de movilidad social en sentido ascendente, sólo para algunos de los actores implicados en el rubro. La fuerte presencia de este sector resulta un sello interesante del dinamismo en el proceso capitalista local.

Por otra parte, el cotejo con las cédulas censales revela la inserción de inmigrantes europeos sobre todo en el segmento medio de riqueza. Si bien la provincia de Tucumán no constituyó una gran receptora de población extranjera en la fase de migración masiva decimonónica, en la temprana época de la década de 1860 cualitativamente ese sector se vinculó a las

\footnotetext{
${ }^{34}$ Campi y Bravo comentan el caso de Wenceslao Posse (estereotipo de la burguesía tucumana decimonónica y el más rico sujeto de toda la provincia según los padrones de contribución directa en la década de 1860) quién emprendió en 1873 la constitución de una firma para importar una máquina de pellones, reflejando la intención de este principal exportador tucumano de potenciar tecnológicamente una tradicional artesanía que afectaba a numerosas familias de la ciudad de San Miguel de Tucumán. Campi y Bravo, "Mujer”, 1995, p. 148.
} 
actividades más lucrativas (como el comercio y la curtiduría) o también a aquellas que significaban cierta extrañeza o novedad y mínimos conocimientos científico-técnicos: maquinista, relojero, hotelero, médico, botiquero y fotógrafo. Seguramente la poca competencia en el desempeño de estas ramas de actividades urbanas aseguraba mejores rentas e ingresos. A su vez, lograron constituir el sector más concentrado de la riqueza vinculada a las panaderías. En total la inmigración europea en 1869 constituía $0.3 \%$ de la población provincial y $2 \%$ de la población urbana del departamento Capital. En este último espacio geográfico lograban reunir $8 \%$ de los capitales (véase cuadro 4), con un valor promedio de 4000 pesos bolivianos. Queda claro que formaron parte de los sectores medios de riqueza con posibilidades de ascenso social. Según observadores contemporáneos, hacia fines del siglo XIX el inmigrante "se coloca al día siguiente de llegar y es muy solicitado". ${ }^{35}$

Finalmente, había un sector muy por debajo del segmento bajo de riqueza, que según los criterios de la época poseía un capital menor a los 500 pesos bolivianos y que escapaba en su mayoría a los registros. ¿A qué categorías ocupacionales representaban? Sin duda entre los pobres cobran protagonismo grupos dependientes como el servicio doméstico y en menor medida jornaleros y peones. Se añade también la particularidad de $6 \%$ de militares y soldados, dado la presencia de la Guardia Nacional. Pero un dato de suma relevancia es que el grueso de estas actividades sin mínimos registros de riqueza correspondían a oficios que capturaron principalmente el trabajo femenino (del servicio: la mayoría de las sirvientas, cocineras, lavanderas, planchadoras; de la industria textil: costureras, hilanderas, tejedoras). De modo que dentro de los sectores dependientes y de la artesanía doméstica textil el segmento más pobre era el de las mujeres, precisamente en el ámbito espacial, la ciudad, donde ellas constituían la mayoría. Por contraste, las mujeres con riqueza detectadas en el cruce ocupacional eran en su totalidad propietarias inmobiliarias, mayormente viudas y sin declaración de oficio. Ello devela principalmente el acceso de un grupo minoritario de mujeres a patrimonios territoriales por herencia familiar, frente a una predominante fracción femenina menesterosa.

${ }^{35}$ Rodríguez, Provincia, 1890, p. 15. 


\section{FUENTES CONSULTADAS}

\section{Archivos}

AHT Archivo Histórico de Tucumán, San Miguel de Tucumán, Argentina.

Centro de Genealogía de la Iglesia de Los Mormones, San Miguel de Tucumán, Argentina.

\section{Bibliografía}

Álvarez, BEAtriz, "La desigualdad de la riqueza en Tucumán entre 1869 y 1884. Una aproximación a su medición a partir de los inventarios post mortem", Revista Población ES Sociedad, Instituto Superior de Estudios Sociales, vol. 18, núm. 2, 2011, Tucumán, pp. 107-144.

Bolsi, Alfredo y PATricia D’Arterio, “Agroindustria azucarera y mortalidad: análisis comparado de cuatro complejos latinoamericanos", Revista Theomai, núm. 12, segundo semestre de 2005, en <http://revista-theomai.unq.edu.ar/numero12/ art_bolsi_12.htm $>$. [Consulta: 1 de abril de 2013.]

Bousquet, Alfredo, Estudio sobre el sistema rentístico de Tucumán, de 1820 a 1876, Tucumán, Imprenta La Razón, [1878], reedición de la Fundación Banco Comercial del Norte, 1971.

Burmeister, Germán, Descripción de Tucumán, Buenos Aires, Imprenta y Casa Editora de Coni Hnos., [1855], reedición de la Universidad Nacional de Tucumán, Tucumán, 1916.

CAMPI, DANiEL, "Notas sobre la gestación del mercado de trabajo en Tucumán (18001870), Revista Población ES Sociedad, Instituto Superior de Estudios Sociales, núm. 5, octubre de 1999, pp. 133-163.

"Los ingenios del Norte: un mundo de contrastes" en Fernando Devoto y Marta Madero (coords.), Historia de la vida privada en la Argentina. La Argentina plural: 1870-1930, Buenos Aires, Taurus, 1999, t. 2.

, "Notas sobre la gestación del mercado de trabajo en Tucumán (18001870)" en Jorge Gelman, Juan Carlos Garavaglia y Blanca Zeberio (comps.), Expansión capitalista y transformaciones regionales, Buenos Aires, La Colmena/Universidad del Centro de la Provincias de Buenos Aires, 1999.

"Economía y sociedad en las provincias del Norte" en ZAIDA M. LOBATO (comp.), Nueva historia argentina. El progreso, la modernización y sus límites (18801916), Buenos Aires, Sudamericana, 2000.

"Aproximación a la génesis de una elite azucarera. Las exportaciones tucumanas en carreta, 1863-1867", Travesía. Revista de Historia Económica y Social, Universidad Nacional de Tucumán, núms. 5-6, 2000-2001, pp. 129-179.

"Espacio mercantil, unidades de producción y actores en los orígenes de la agroindustria del azúcar en Tucumán, 1830-1870” en AlBerTo VIERA et al., 
Histórica do açúcar. Rotas e mercados, Funchal, Centro de Estudos de História do Atlántico, 2002, pp. 335-364.

"Azúcar y trabajo. Coacción y mercado laboral. Tucumán, 1856-1896”, tesis doctoral inédita, España, Universidad Complutense de Madrid, 2002.

Campi, Daniel y Ma. Celia Bravo, "La mujer en Tucumán a fines del siglo XIX. Población, trabajo, coacción” en ANA TERUEL (comp.), Población y trabajo en el noroeste argentino. Siglos XVIII y XIX, Jujuy, Universidad Nacional de Jujuy, 1995, pp. 143-170.

Campi, Daniel y Rodolfo Richard Jorba, "Las tendencias a la formación del mercado interno. Las producciones regionales extrapampeanas" en MARTA BONAUDO (coord.), Liberalismo, Estado y orden burgués, 1852-1880. Nueva historia argentina, Buenos Aires, Sudamericana, 1999, t. IV.

Crespo, Horacio (coord.), El azúcar en América Latina y el Caribe. Cambio tecnológico, trabajo, mercado mundial economía azucarera. Perspectivas históricas y problemas actuales, México, Senado de la República, 2006.

Fandos, Cecilia A. y Patricia I. Fernández Murga, "Sector comercial e inversión inmobiliaria en Tucumán (1800-1850)", Travesía. Revista de Historia Económica y Social, Universidad Nacional de Tucumán, núms. 5-6, 2000-2001, pp. 181-232.

GALlO, CÉSAR, “Crecimiento y desigualdad. Actualidad de una vieja paradoja”, Revista Venezolana de Economía y Ciencias Sociales, Universidad Central de Venezuela, vol. 9, núm. 3, septiembre-diciembre de 2003, pp. 57-79, en <http://www.redalyc.org/ pdf/177/17709304.pdf>. [Consulta: 29 de marzo de 2013.]

Gelman, Jorge y Daniel Santilli (comps.), El mapa de la desigualdad en Argentina, siglo XIX, Rosario, Prohistoria, 2011, pp. 261-301.

Giménez Zapiola, MARCos, “El interior argentino y el 'desarrollo hacia afuera': el caso de Tucumán” en MARCOS Giménez ZAPIOLA (comp.), El régimen oligárquico. Materiales para el estudio de la realidad argentina (hasta 1930), Buenos Aires, Amorrortu, 1975.

Granillo, Arsenio, Provincia de Tucumán, Tucumán, Imprenta de La Razón, 1872.

HorA, RoY, Historia económica de la argentina en el siglo XIX, Buenos Aires, Siglo XXI, 2010.

Lizondo Borda, Manuel (comp.), Tucumán a través de la historia. El Tucumán de los poetas, Tucumán, Imprenta Prebisch y Violetto, 1916.

LÓPez de Albornoz, CRistina, Los dueños de la tierra. Economía, sociedad y poder en Tucumán (1770-1820), Tucumán, Universidad Nacional de Tucumán, 2003.

LÓPEZ, CRISTINA, "Arrieros y carreteros tucumanos, 1786-1810”, Revista Andes, Antropología e Historia, Centro Promocional de Investigaciones en Historia y Antropología Dr. Guillermo Madrazo, núm. 6, 1996, Salta, pp. 89-122.

Parolo, María PAula, "Criadores, labradores, capataces y peones en la campaña tucumana en la primera mitad del siglo XIX", Anuario del Instituto de Estudios Históricos y Sociales, Universidad Nacional del Centro, núm. 15, 2000, Tandil, pp. 353-380. 
"Estructura socioocupacional y sectores populares en Tucumán. Primera mitad del siglo XIX", tesis doctoral, Argentina, Universidad Nacional de Tucumán, 2003.

"Actores económicos y categorías ocupacionales. Los sectores mercantiles en Tucumán, 1800-1870”, Boletín del Instituto de Historia Argentina y Americana Dr. Emilio Ravignani, núm. 27, primer semestre de 2005, Buenos Aires, pp. 75-106.

"Nociones de pobreza y políticas hacia los pobres en Tucumán en la primera mitad del siglo XIX", Revista Población E Sociedad, Fundación Yocavil, vol. 12, núm. 1, 2005-2006, Tucumán, pp. 133-163.

"Ni súplicas, ni ruegos". Las estrategias de subsistencia de los sectores populares en Tucumán en la primera mitad del siglo XIX, Rosario, Prohistoria, 2008.

"La presión fiscal sobre el comercio en Tucumán durante el siglo XIX", Revista Escuela de Historia, Universidad Nacional de Salta, vols. 1 y 2, núm. 10, 2011, pp. 109-131.

y Cecilia Fandos, “Tierra, ganado y giro comercial. La distribución de la riqueza en la 'próspera' Tucumán de la década de 1860" en Jorge Gelman y Daniel Santilli (comps.), El mapa de la desigualdad en Argentina, siglo XIX, Rosario, Prohistoria, 2011, pp. 261-301.

Primer censo de la república argentina, 1869, Buenos Aires, Imprenta del Porvenir, 1872.

Rodríguez Marquina, Paulino, La provincia de Tucumán. Breves apuntes, Tucumán, Tip. y Encuadernación de El Orden, 1890.

SÁnchez Román, José Antonio, "La industria azucarera en Argentina (1860-1914): el mercado interno en una economía exportadora", Revista de Indias, Consejo Superior de Investigaciones Científicas, vol. 65, núm. 233, 2005, pp. 147-172.

Zamora, Romina, "Abasto urbano y economía en San Miguel de Tucumán a fines del siglo XVIII y comienzos del XIX. Los criterios de antiguo régimen", Nuevo Mundo Mundos Nuevos, Debates, publicado en línea el 31 de enero de 2011, en <http:// nuevomundo.revues.org/6057>, DOI: 10.4000/nuevomundo.60571. [Consulta: 11 de agosto de 2013.] 